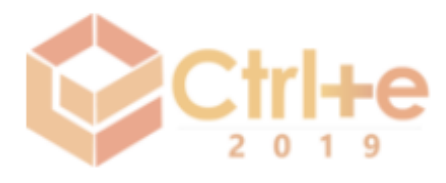

IV Congresso sobre Tecnologias na Educação (Ctrl+E 2019)

Recife, Pernambuco - Brasil

28 a 30 de agosto de 2019

\title{
Recurso Educacional Digital (RED) para Trabalhar o Gênero Cardápio: Qual é o seu Pedido?
}

\author{
Raquel S. Freire1, Mércia V. Campos Figueiredo1, Rayssa A. Hitzschky1, Danilo C. \\ Sousa1, Francisco Gilson G. Júniorı, José Aires de Castro Filho1 \\ 1Instituto UFC Virtual - Universidade Federal do Ceará (UFC) \\ Caixa Postal 60440-554 - Fortaleza - CE - Brasil \\ \{freire, gilsonjunior, aires\}@virtual.ufc.br, \{merciaval42, \\ sir.danilo.coelho, hitzschkyrayssa\}@gmail.com
}

\begin{abstract}
Resumo. O RED "Qual é o seu pedido?" foi desenvolvido a partir das concepções da Base Nacional Comum Curricular (BNCC), com o objetivo de trabalhar com a leitura e a produção de cardápios. Por meio de situações de interação com o gênero, este recurso explora a compreensão do cardápio a partir de sua funcionalidade e organização composicional, tais como entrada, prato principal, sobremesa e bebida. Com o desenvolvimento do recurso, espera-se trazer um repertório de pratos diversificados, de maneira que os estudantes em processo de alfabetização e de letramento possam observar diferentes ortografias, ampliar seu vocabulário e conhecimento de mundo e perceber como a culinária envolve uma construção histórica e cultural.
\end{abstract}

Abstract. The RED "What is your request?" was developed from the conceptions of the National Curricular Joint Base (BNCC), with the objective of working with the reading and the production of menus. By means of situations of interaction with the genus, this resource explores the understanding of the menu from its functionality and compositional organization, such as entry, main course, dessert and drink. With the development of the resource, it is hoped to bring a repertoire of diversified dishes, so that students in the process of literacy and literacy can observe different spellings, expand their vocabulary and world knowledge and realize how the cuisine involves a historical construction and cultural development.

\section{Justificativa Pedagógica}

As tecnologias digitais vêm sendo amplamente utilizadas em nosso cotidiano e em ambientes educacionais formais. Pesquisas apontam que Recursos Educacionais Digitais (RED) estão sendo cada vez mais produzidos para que sejam utilizados em sala de aula [Scacchetti e Guarienti, 2015; Soares, Souza e Castro, 2018]. De uma forma geral, os RED são materiais em formato digital com objetivos pedagógicos bem definidos [Amiel e Santos 2013], nos quais estes podem auxiliar os processos de ensino e de aprendizagem, bem como a compreensão de conteúdos.

Devido a importância de RED em sala de aula, torna-se relevante que o seu desenvolvimento seja fundamentado a partir das habilidades previstas na Base Nacional Comum Curricular (BNCC). A BNCC é um documento de caráter normativo que define 
conhecimentos, competências e habilidades essenciais que todos os alunos devem desenvolver ao longo da Educação Básica [Brasil 2017].

Por isso, faz-se necessário investigar como estes recursos podem ser desenvolvidos para atender aos objetivos de aprendizagem apresentados pela BNCC. Dessa forma, o objetivo deste trabalho é apresentar como um RED de Língua Portuguesa foi desenvolvido no âmbito do projeto Mídias Interativas Educacionais (MIDE) para os anos iniciais do Ensino Fundamental. O projeto é fruto de uma parceria entre o Grupo de Pesquisa e Produção de Ambientes Interativos e Objetos de Aprendizagem (PROATIVA), o Laboratório de Mídias Educacionais (LME) e o Ministério da Educação (MEC). O recurso Qual é o seu pedido? 1 busca ampliar as práticas de alfabetização e de letramento por meio de um gênero textual recorrente no cotidiano: o cardápio. Segundo a BNCC [Brasil 2017], o campo da vida cotidiana tem como propósito trabalhar com situações de leitura decorrentes do espaço familiar, escolar, cultural e profissional. O documento apresenta como gêneros textuais deste campo: agendas, listas, bilhetes, recados, avisos, convites, cartas, cardápios, diários, receitas, regras de jogos e brincadeiras. Nesse sentido, o RED enfatiza o desenvolvimento de tais habilidades:

(EF15LP01) - Identificar a função social de textos que circulam em campos da vida social dos quais participa cotidianamente (a casa, a rua, a comunidade, a escola) e nas mídias impressa, de massa e digital, reconhecendo para que foram produzidos, onde circulam, quem os produziu e a quem se destinam.

(EF15LP03) - Localizar informações explícitas em textos. (BRASIL, 2017, p. 95)

Na seção seguinte, o processo de desenvolvimento e as ferramentas tecnológicas utilizadas para a produção do recurso serão descritas. Depois, serão apresentados os potenciais usos do RED em processos de ensino e de aprendizagem e os impactos esperados na educação.

\section{Processo de Desenvolvimento e Ferramentas Tecnológicas Utilizadas}

A metodologia adotada no desenvolvimento do RED Qual é o seu pedido? baseou-se em práticas de Engenharia de Software, conhecidas como metodologias ágeis, uma vez que priorizam testes e uso de técnicas de engenharia de requisitos [Lapolli et al. 2010]. Metodologias ágeis são um processo de desenvolvimento interativo e incremental de software, organizado em pequenas equipes, no qual existe entrega constante, em curto intervalo de tempo, com uma participação contínua de todos os membros [Beck et al. 2001; Cockburn 2006].

O desenvolvimento do RED envolveu uma equipe multidisciplinar composta por duas equipes: a) equipe pedagógica, incluindo pedagogos e graduados em Letras, que concebeu a proposta educacional do recurso, a partir da contextualização de seus objetivos e conteúdos, bem como descreveu o roteiro pedagógico com a narrativa, as atividades, os feedbacks, além de referências visuais; b) equipe de desenvolvimento, que englobou roteiristas, designers, ilustradores, programadores e gerente de projeto. Essa 
equipe desenvolveu a identidade visual do RED, conforme a proposta pedagógica, as telas, os ícones, os cenários e os personagens. Ao final, a identidade visual foi implementada, sob supervisão de um gerente de projeto e de um coordenador geral, que organizaram todo o processo. De acordo com a metodologia ágil, essas características heterogêneas da equipe têm o objetivo de criar tensões durante o processo de desenvolvimento. Para a criação do RED, as equipes reuniram-se semanalmente para discutir os produtos [Braga 2015] em cada uma das etapas a seguir (Figura 1):

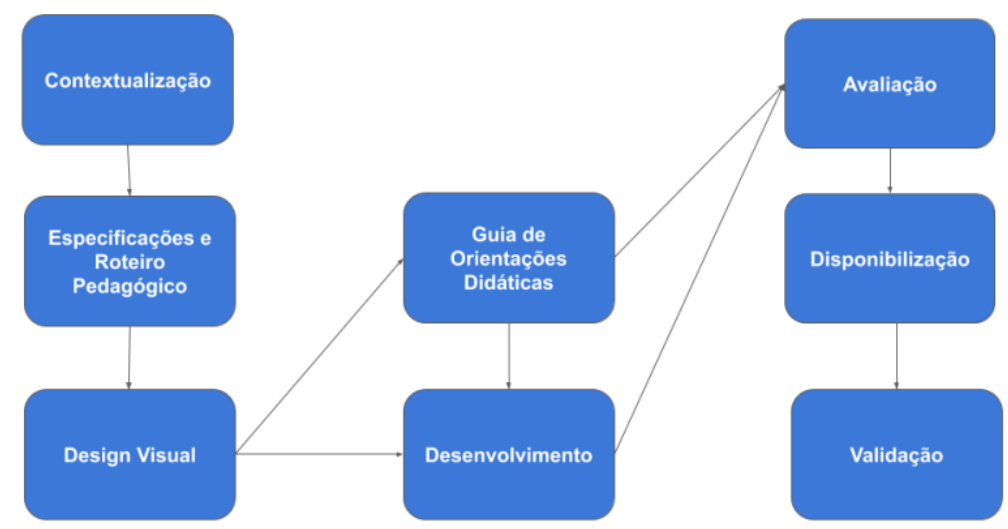

Figura 1. Etapas de desenvolvimento do RED Qual é o seu pedido?

A primeira etapa, Contextualização, foi antecedida pelos estudos da BNCC e compreendeu a concepção inicial do recurso, assim como a delimitação de possíveis abordagens para o conteúdo. A segunda etapa, Especificações e Roteiro pedagógico, constou da elaboração de um documento, denominado roteiro pedagógico, que mostrou como o conteúdo do RED deveria ser estruturado. Estas etapas foram realizadas pela equipe pedagógica, com colaboração do roteirista.

A terceira etapa, Design Visual, contemplou a concepção visual do recurso, abrangendo a ilustração de personagens, cenários e tipografia, e foi feita pelos designers e ilustradores. A quarta etapa, Desenvolvimento, envolveu a programação do RED que utilizou a linguagem HTML5 com Java Script. Teve-se como preocupação o uso offline do recurso, a fim de antecipar alternativas para possíveis problemas de Internet.

A quinta etapa, Guia de Orientações Didáticas, compreendeu a elaboração de um guia para o professor, com o objetivo de orientá-lo para a utilização do RED fundamentado na BNCC. Esta etapa aconteceu paralelamente à etapa de Desenvolvimento, tendo em vista que, à medida que a equipe pedagógica elaborava o documento, os programadores implementavam o recurso.

A etapa de Avaliação incluiu a realização de testes pedagógicos do RED e do guia, feitos pela equipe pedagógica em colaboração com a de desenvolvimento. Nesta etapa, os responsáveis pela concepção do RED e do guia verificaram se o que foi idealizado estava compatível com o que foi implementado. Ainda nesta etapa, foi feita a revisão textual do recurso e do guia por uma profissional da área externa ao projeto.

A etapa de Disponibilização abrangeu a inserção do RED na Plataforma MEC de Recursos Educacionais Digitais. Por fim, a última etapa será a de Validação, que incluirá testes com alunos dos anos iniciais do Ensino Fundamental, público-alvo do recurso, além de professores, que poderão planejar, juntamente com a equipe 
pedagógica, a inserção do recurso em suas aulas. O objetivo desta fase será o de averiguar a efetividade pedagógica do RED, com foco nas habilidades da BNCC.

\subsection{Perspectiva de Desenvolvimento Pedagógico}

O RED Qual é o seu pedido? buscou-se fundamentar na perspectiva sócio-histórica, vinculada diretamente às teorias de Vygotsky, partindo da observação de que o conhecimento é construído - e não transmitido - e de que os estudantes possuem um papel ativo no processo de aprendizagem.

O RED apropria-se da capacidade dos estudantes, como jogadores, quando são levados a fazer associações, de trazer suas memórias e de usá-las como suporte para a sua vivência em games e espaços gamificados. O uso de atividades gamificadas, como RED no contexto da educação formal, deve oferecer propostas interativas em relação aos objetivos pedagógicos, encorajar a independência e a capacidade de compreensão da inter-relação de pessoas e fatores diversos nas atitudes tomadas [Aguiar 2010]. A gamificação, assim, é uma estratégia com a qual o indivíduo pode passar a viver uma narrativa cujo desenvolvimento depende de sua ação e da qualidade de sua imersão no papel de protagonista de uma ficção com propósitos diversos.

A mediação torna-se, nessa perspectiva, um aspecto importante para se compreender a abordagem socioconstrutivista, conforme Vygotsky afirma: que ela pode se dar por meio de um instrumento como uma ferramenta material ou um signo, uma ferramenta psicológica ou por meio dos próprios seres humanos. Um game, portanto, na perspectiva sócio-histórica, permite à criança ganhar propriedade sobre o mundo sociocultural em que vive, compreendendo as regras de seu funcionamento e dando novos sentidos e significados para o que lhe é apresentado.

\section{Contribuições para os Processos de Ensino e de Aprendizagem}

Cotidianamente, as crianças participam de situações de comunicação, reconhecendo os diferentes usos sociais da leitura e da escrita. Nesse sentido, a educação formal tem como um dos seus objetivos a formação de leitores autônomos [Lerner 2002]. Nos dois primeiros anos do Ensino Fundamental, o foco volta-se para a alfabetização, a fim de garantir múltiplas oportunidades de apropriação do sistema de escrita alfabética pelos alunos, de modo articulado às habilidades de leitura e de escrita dentro de práticas diversificadas de letramento.

Entende-se que, por meio dos processos de alfabetização e de letramento, os alunos são estimulados a estabelecerem uma maior participação, autonomia e protagonismo nas instâncias sociais. A partir desse viés, o recurso aqui descrito busca trabalhar com as habilidades voltadas para a apropriação do código linguístico, porém não de forma isolada. Traçou-se como parâmetro a centralidade do texto [Bakhtin 1997], relacionando-o aos seus contextos de produção, buscando trabalhar com a linguagem de forma significativa em atividades de leitura e de produção de textos.

O RED Qual é o seu pedido? parte do desenvolvimento da competência leitora e escrita aliada ao texto, por meio de seus conteúdos, habilidades e objetivos. Para isso, considerou-se o pertencimento a um gênero discursivo, o cardápio, que circula em um dos campos da vida social, o da vida cotidiana [Geraldi 2015]. 
Buscando apresentar as características composicionais do gênero cardápio de forma autêntica, o recurso está dividido por modos, em que cada um apresenta uma progressão em fases. As fases têm um tempo para a sua realização e o jogador tem um número limitado de tentativas para efetivar as ações solicitadas. Os modos do recurso são: Cliente, Garçom/Garçonete e Chef. O jogador começará pelo modo Cliente, no qual o mapa do Brasil é apresentado e o aluno será situado como um personagem que vai viajar por cidades brasileiras, conhecendo duas regiões: Nordeste e Sul.

Na primeira fase, na região Nordeste, o RED faz uma explicação do gênero e pede que os alunos, no papel de cliente, possam escolher uma entrada, um prato principal e uma sobremesa. Na segunda fase, que se passa na Região Sul, o aluno, ainda no papel de cliente, fará o pedido, mas desta vez deverá estabelecer um valor máximo para a conta. O aluno deverá, então, ler e considerar os valores para fazer um pedido que não ultrapasse cinquenta reais.

Nas fases seguintes, o RED passará para o modo Garçom/Garçonete, no qual o mapa do Brasil é novamente apresentado, com as fases nas regiões Norte, Sudeste e Centro-Oeste. Nessas fases não se considera o valor dos pratos, mas sim o reconhecimento da escrita a partir do que é escutado no RED. Nestas as fases, o aluno escutará uma gravação de um pedido e escolherá no cardápio o que escutou da gravação. Por fim, no modo Chef, trabalha-se com a produção textual de um cardápio, tendo à disposição itens nas seções, entre eles entrada, prato principal, sobremesa e bebida, criando um cardápio diversificado, à escolha do aluno. Espera-se, dessa forma, que o recurso ofereça subsídios para que os alunos compreendam as características do gênero cardápio, ao mesmo tempo em que trabalhem com a leitura e a produção escrita. A partir dos elementos de gamificação presentes no RED, objetiva-se tornar a experiência de aprendizagem divertida e engajadora. Além disso, o recurso busca contribuir para a diversificação dos conhecimentos acerca da culinária brasileira, que é tão rica em história e cultura. Na seção seguinte, apresenta-se os impactos esperados na educação com a utilização do recurso em questão.

\section{O Uso e os Impactos Esperados na Educação}

Dentro do ambiente escolar, o RED Qual é o seu pedido? pode ser usado de duas formas: individualmente ou em grupo. Ao se trabalhar em grupo, a discussão entre os alunos pode envolver a narrativa e os desafios presentes no jogo, favorecendo a construção da aprendizagem por cada um. Além disso, jogar com os amigos pode se constituir um momento mais atrativo para os alunos, contribuindo para a imersão no jogo. As experiências prévias dos estudantes, combinadas com as mecânicas e os elementos de gamificação, bem como a atuação do professor como mediador, podem possibilitar uma experiência de aprendizagem na área de Língua Portuguesa com um potencial dinâmico e mais afetivo. Como uma forma de atividade ainda inusitada no ambiente de sala de aula, o RED pode ter o potencial de produzir interações a partir das simulações propostas, como também o desenvolvimento da linguagem e da escrita.

Deve-se ressaltar que, para que o RED Qual é o seu pedido? tenha seu potencial de aplicação devidamente alcançado, deve-se levar em consideração todo o contexto social e educacional no qual ele será inserido. Um mero estímulo externo ou a intenção do educador não determinará a qualidade e o sucesso do seu uso. Esse sucesso será 
determinado pelo conjunto e pelo coletivo envolvido no processo educacional e pelo potencial mediador dos professores durante a utilização do recurso.

Destaca-se, desse modo, a importância da mediação do professor e, igualmente, da geração de um fluxo de feedbacks entre os desenvolvedores e aqueles que aplicarão e utilizarão o RED em sala de aula, para fins de aprimoramento. Durante a sessão de utilização, o professor poderá auxiliar os alunos, ajudando-os nos problemas matemáticos que surgem em alguns dos pedidos ou apontando conteúdos e habilidades socioemocionais que talvez passem despercebidos às crianças. Nesse contexto, esperase que com a utilização do RED, os alunos possam desenvolver aspectos cognitivos, sociais e emocionais e, assim, possam ampliar os processos de alfabetização e de letramento, o seu repertório linguístico, considerando outras variedades, de modo que eles sejam capazes de usar sua língua materna de forma eficiente em vários contextos de interação. Além disso, almeja-se que o aluno possa compreender a função do cardápio em sua vida cotidiana.

\section{Considerações Finais}

O desenvolvimento de um RED deve estar pautado em uma diversidade de fatores que variam de uma ordem legislativa na educação (como atender às regras de um documento norteador, como a BNCC), uma ordem teórica (como a fundamentação na perspectiva sócio-histórica), uma ordem técnica (como a definição de uma mecânica), uma ordem pedagógica (como a definição de intencionalidades pedagógicas) e uma ordem afetiva (como o estudo sobre o meio no qual o RED será inserido como base para o desenvolvimento de possíveis afetos para identificação por parte dos alunos). O RED Qual é o seu pedido? opera, nessa perspectiva, na complexidade de tal empreendimento, promovendo maior consciência da significância de atender a esses fatores. Por meio do RED, os alunos podem entrar em contato com o gênero cardápio de forma contextualizada, a partir de uma narrativa gamificada que inclui diferentes linguagens, como a textual, visual e sonora. O recurso, ainda, traz diversas situações nas quais os alunos podem vivenciar a função social do cardápio, desde a sua utilização mais imediata até aspectos que dão forma ao gênero, como o nome do estabelecimento, evidenciando regularidades de tamanho, posição no espaço do texto, cor, tamanho e tipografia; a divisão em seções que, por vezes, trazem informações adicionais, como os ingredientes que compõem os pratos; o portador do cardápio, que inclui meios convencionais como o papel ou quadros ou aqueles mais contemporâneos, como suportes eletrônicos: smartphones, tablets, entre outros.

A produção textual oferecida ao final do RED em suporte digital possibilita uma maior interação com o gênero, pois, usando a rede, torna-se mais fácil fazê-lo circular e ser lido por outras pessoas nos formatos disponibilizados para exportação (.jpeg e .pdf). $\mathrm{O}$ desenvolvimento prático do gênero estimula que o aluno possa relacionar o que foi estudado anteriormente ao longo das fases do RED à composição de um cardápio, evidenciando a ocorrência ou não da aprendizagem das características do gênero.

A produção escrita também possibilita o desenvolvimento de uma avaliação formativa, que inclui o rascunho, a elaboração de uma primeira versão, a revisão do texto e a versão final. É importante destacar que a compreensão do gênero pelo aluno deve ser entendida como um processo e não apenas como fruto dos seus resultados finais. Para isso, a realização de cada fase e a conquista das recompensas pode refletir o 
nível de entendimento dos alunos em relação às atividades propostas, paralelamente, à proposição de atividades anteriores que tratam o gênero cardápio. Durante $o$ desenvolvimento do recurso, a equipe do projeto também produziu um Guia de Orientações Didáticas, entendendo que o uso de RED não deve acontecer de forma isolada, mas sim por meio de um suporte pedagógico voltado para o professor, permitindo o trabalho com sequências didáticas diversas e inter-relacionadas. Desse modo, o RED Qual é o seu pedido? configura-se como um instrumento de interação e construção de conhecimentos que podem ser utilizados dentro do componente curricular de Língua Portuguesa, visando a ampliação da alfabetização e do letramento.

\section{Referências}

Aguiar, M. P. (2010) “Jogos Eletrônicos Educativos: Instrumento de Avaliação focado nas fases iniciais do processo de design”. Universidade Federal do Paraná. Programa de Pós-Graduação em Design.

Amiel, T.; Santos, K. (2013) "Uma análise dos termos de uso de repositórios de recursos educacionais digitais no Brasil." Trilha Digital, v.1, p.118-133.

Bakhtin, M. M. (1997) "Estética da criação verbal". $2^{\circ}$ ed. São Paulo: Martins Fontes.

Beck, K.; Cockburn, A.; Jeffries, R.; Highsmith, J. (2001) "Agile Manifesto". Disponível em: < http://agilemanifesto.org/>. Acesso em 01 de Jul. 2019.

Braga, J. (2015) "Objetos de Aprendizagem: metodologia de desenvolvimento". Volume 2, Santo André: Editora da UFABC. 163p.

Brasil. (2017) "Base Nacional Comum Curricular". Brasília, DF: MEC.

Cockburn, A. (2006) "Agile Software Development". [s.1.] Pearson Education.

Geraldi, J. W. (2015) "O ensino de língua portuguesa e a Base Nacional Comum Curricular". Revista Retratos da Escola, Brasília, v. 9, n. 17, p. 381-396, jul./dez.

Lapolli, F; Cruz, C. M.; Motta, C. L. R.; Tolla, C. E. T. (2010) "Modelo de Desenvolvimento de Objetos de Aprendizagem Baseado em Metodologias Ágeis e Scaffoldings.” Revista Brasileira de Informática na Educação, Volume 18, nº 2.

Lerner, D. (2002) "Ler e escrever na escola: o real, o possível e o necessário". Ed. Artmed: Porto Alegre. 128p.

Scacchetti, F. A. P. and Guarienti, N. (2015) "Desenvolvimento de Recursos Educacionais Digitais Aplicados no Ensino de Tecelagem.” Ponto Revista Científica, v. 1, n. 2, dez.

Soares, C. G.; Souza, D. C.; Castro, J. B. (2018). "Recursos Educacionais Digitais e o ensino de adição e subtração: a concepção de um jogo na perspectiva da Teoria dos Campos Conceituais." VII Congresso Brasileiro de Informática na Educação (CBIE 2018), Anais do VII Congresso Brasileiro de Informática na Educação. 